\title{
Cutaneous Leishmaniasis: A Neglected Vector Borne Tropical Disease in Midwestern Region of Nepal
}

\author{
Ghimire PG ${ }^{1}$, Shrestha $\mathbf{R}^{1}$, Pandey $\mathrm{S}^{2}$, Pokhrel K², Pande $\mathbf{R}^{3}$ \\ ${ }^{1}$ Department of Pathology; ${ }^{2}$ Department of Dermatology and Venereology, Nepalgunj Medical College and Teaching \\ Hospital, Banke, Nepal, ${ }^{3}$ Department of Internal Medicine, Bheri Zonal Hospital, Nepalgunj
}

\begin{abstract}
Introduction: Cutaneous Leishmaniasis is a vector borne disease caused by the bite of an infected sandfly. The disease is rare in Nepal with only few cases reported till date. We report the largest collection of patients over six years.

Objective: To describe the clinical, epidemiological and pathological aspect of Cutaneous Leishmaniasis in Midwestern region of Nepal

Materials and Methods: Thirty-three patients referred to the department of Pathology for fine needle aspiration were diagnosed as Cutaneous leishmaniasis based on detection of Leishmania donovani in the fine needle aspiration smears. Demographic data and clinical details including site, size, and duration of disease onset were recorded on a printed proforma. Statistical analysis was done using SPSS version 16.0 for windows.

Results: A total of 33 patients with age ranging from 11 years to 65 years were included in the study. Mean age was $26.5 \pm 11.5$ years. Most patients were in the age group 21-40 years. Male: Female ratio was 1.7:1. Mean duration of disease was $5.3 \pm 4.4$ months. Thirty patients had single lesion. Lesions were either of plaque type (84.9\%) or papulonodular type (15.1\%).

Conclusion: Cutaneous leishmaniasis is uncommon in Nepal. So, it is often neglected. It is in an increasing trend. Cutaneous leishmaniasis should be included in the differential diagnosis of a non-healing ulcer.

Key words: Biopsy, fine-needle; disease vectors; Leishmania, cutaneous; Nepal; Phlebotomus; ulcer
\end{abstract}

\section{Introduction}

C utaneous leishmaniasis $(\mathrm{CL})$ is the most common form of Leishmaniasis. ${ }^{1}$ According to the data of World Health Organization, India is endemic for cutaneous leishmaniasis. ${ }^{2}$ Though visceral leishmaniasis is common in Terai region; cutaneous leishmaniasis is rare in Nepal. Only few cases have been reported from Nepal. ${ }^{3-7}$ It is a parasitic disease transmitted by sandfly infected with the protozoa Leishmania. Cutaneous leishmaniasis occurs at the site of inoculation. The incubation period between the bite of infected sandfly to development of lesion is 2 weeks to 6 months. It is caused by $L$. tropica, L. major, and L. aethiopica in the old world and by L. Mexicana, L. amazonensis, and L. braziliensis in the New World. ${ }^{8}$ Clinical manifestation range from

\section{Address of Correspondence:}

Dr. Pragya Gautam Ghimire

Assistant Professor

Department of Pathology, Nepalgunj Medical College and Teaching Hospital, Banke, Nepal

E-mail: drpragya@gmail.com painless spontaneously healing nodulo-ulcerative lesion to disfiguring ulcers. Healed lesions often leave residual atrophic scars. ${ }^{9}$

In Nepal, the first case of cutaneous leishmaniasis was reported in 2006 by Pandey BD et al. ${ }^{2}$ Since then the prevalence of the disease is slowly rising. Here we report a largest collection of cases over the six years period. The aim of the study was to describe the

Submitted: $15^{\text {th }}$ January 2018

Accepted: $28^{\text {th }}$ February 2018

Published: $21^{\text {st }}$ March 2018

How to cite this article

Ghimire PG, Shrestha R, Pandey S, Pokhrel K, Pande R. Cutaneous leishmaniasis: A neglected vector borne tropical disease in midwestern region of Nepal. Nepal Journal of Dermatology Venereology and Leprology. 2018;16(1):41-4. doi: http://dx.doi.org/10.3126/njdvl.v16i1.19405

\section{(c) (i)}

Licensed under CC BY 4.0 International License which permits use, distribution and reproduction in any medium, provided the original work is properly cited. 
clinical, epidemiological and pathological aspect of $\mathrm{CL}$ in Mid-western Nepal.

\section{Materials and Methods}

The present study includes patients with nonhealing ulcer referred from Surgery, ENT and Medicine departments and also clinically suspected cases of cutaneous leishmaniasis who came to the Dermatology department of Nepalgunj Medical College and Teaching Hospital, Banke during the period of six years; from January 2012 to November 2017. All the patients were referred to the department of Pathology for impression smear/fine needle aspiration (FNA).

Demographic data and clinical details including site, size, and duration of disease onset were recorded on a printed proforma. Each patient was asked about travel history outside the country.

Fine needle aspiration was done from all lesions from the base of the ulcer using 23-gauge needle and $10 \mathrm{ml}$ syringe for suctioning. Skin scrapping and slit skin smears were not made in any of our cases. The air-dried smears were then stained with Giemsa stain. Two of our cases came to our hospital with non-healing surgical wound, for which excision of the primary wound was done outside. These two cases were subjected to FNA and biopsy followed by histopathology. Diagnosis of $\mathrm{CL}$ was made based on detection of Leishmania donovani (LD) body in the smears. All of our patients were positive for LD bodies. SPSS version 16 for windows was used for statistical analysis.

Approval letter from the institutional review board was obtained before starting the study.

\section{Results}

This prospective study is a review of patients with cutaneous Leishmaniasis diagnosed by fine needle aspiration cytology and histopathology over the period of 6 years. A total of 33 patients ranging from 11 years to 65 years with mean age of $26.5 \pm 11.5$ years were diagnosed during the six years period. Most of the patients were in the $21-40$ years age group (Table 1 ). There were 21 male patients and 12 female patients. Male: female ratio was 1.7:1. Most of the patients were from Kalikot (Table 2).

Duration of the disease at the time of presentation ranged from one month to 24 months with mean duration of $5.3 \pm 4.4$ months. None of the patients could give history of insect bite or trauma. Three patients gave history of travel to India in the preceding
2 years. Rest of the patients denied history of travel in the preceding 2 years.

Thirty patients $(90.9 \%)$ had single lesion (Figure 2). Among the remaining patients, lesions were multiple. Among the single lesions most of them were in the face (Table 3). Among the facial lesions the lesions were concentrated over the nose, angle of mouth, lips, cheeks, forehead, chin and submandibular region. Submental lymphadenopathies were seen in two patients with lower lip involvement. In three patients (9.0\%) the lesions were either on the shoulder or dorsum of hand or forearm.

Lesions were either of plaque type (85\%) or papulonodular type (15.1\%). Red, ulcerated plaque was more commonly seen as compared to non-ulcerated plaque. Eighteen patients had ulcerated plaque.

All the patients denied history of fever and had no signs of systemic involvement on examination.

Table 1: Distribution of patients according to age group.

\begin{tabular}{|c|c|c|}
\hline Age group (years) & Frequency & Percentage \\
\hline$\leq 20$ & 13 & 39.4 \\
\hline $21-40$ & 18 & 54.5 \\
\hline $41-60$ & 1 & 3 \\
\hline $61-80$ & 1 & 3 \\
\hline Total & $\mathbf{3 3}$ & $\mathbf{1 0 0}$ \\
\hline
\end{tabular}

Table 2: Distribution of patients according to district.

\begin{tabular}{|c|c|c|}
\hline Address & Frequency & Percentage \\
\hline Banke & 4 & 12.12 \\
\hline Surkhet & 5 & 15.15 \\
\hline Jumla & 1 & 3.0 \\
\hline Dolpa & 8 & 24.2 \\
\hline Salyan & 1 & 3.0 \\
\hline Kalikot & 10 & 30.30 \\
\hline Rolpa & 2 & 6.1 \\
\hline Kailali & 2 & 6.1 \\
\hline Total & 33 & 100 \\
\hline
\end{tabular}

Table 3: Distribution of the lesions in patients with solitary lesion.

\begin{tabular}{|l|c|c|}
\hline Sit of the lesion & Frequency & Percentage \\
\hline Face & 26 & 86.7 \\
\hline Upper Limb & 3 & 10 \\
\hline Trunk & 1 & 3.3 \\
\hline Total & $\mathbf{3 0}$ & $\mathbf{3 0}$ \\
\hline
\end{tabular}

All the patients were positive for LD bodies in smears. 


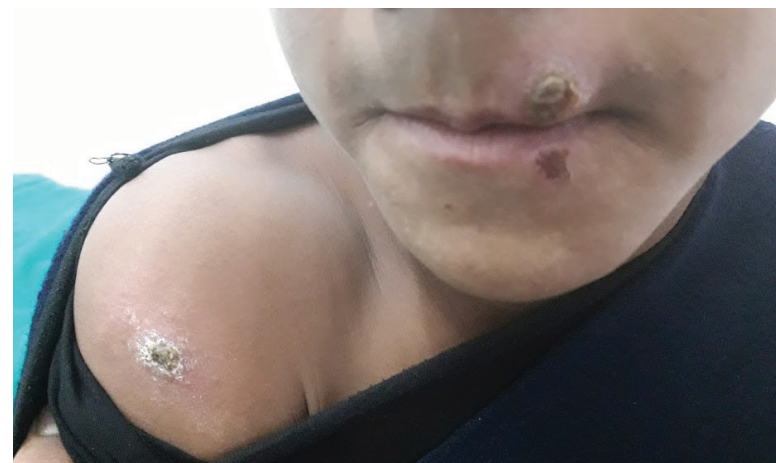

Figure 1: Non healing ulcer in the upper, lower lip as well as lateral aspect of the right upper arm.

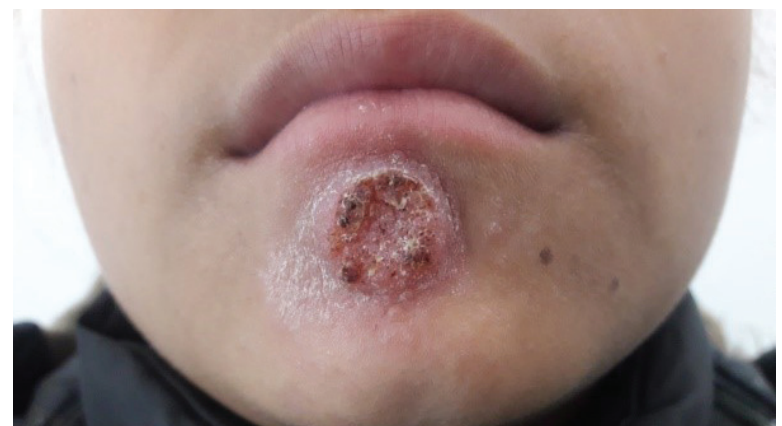

Figure 2: Erythematous plaque with crust in lower lip area involving mentolabial sulcus.

\section{Discussion}

Cutaneous leishmaniasis is a significant public health problem transmitted by sandfly. The disease is endemic in places with dry and hot environment, which is favorable for breeding of sandfly. Till date only few cases have been reported in Nepal.

In the present study, highest number of patients were in the $21-40$ years age group, which is similar to study by Sharma NL et al. ${ }^{10}$ In contrast, Gurel MS et al found a higher incidence in patients of 5-9 years age group. ${ }^{11}$ Similarly, some authors have found a higher incidence of cutaneous leishmaniasis in the 10-19 years age group. $^{9,12,13}$ The number of patients decreased with advancing age which may be due to acquired immunity.

In the present study, the disease was more common in males with male to female ratio of 1.7:1. This finding is similar to studies done by Aara $\mathrm{N}$ et al $^{9}$ and Srivastava et al. ${ }^{13}$ In contrast, other authors have found a higher incidence of disease in females. ${ }^{11,12}$ In Nepal, females are mostly involved in household works and males are involved in outdoor works. This may have predisposed the males to the bite of sand fly.

In our study, mean duration of disease from the onset of lesion to diagnosis was $5.3 \pm 4.4$ months. Aara $\mathrm{N}$ et al ${ }^{9}$ reported 3.7 months and Sharma et al ${ }^{10}$ reported 6.9 months. Delay in diagnosis was due to misdiagnosis

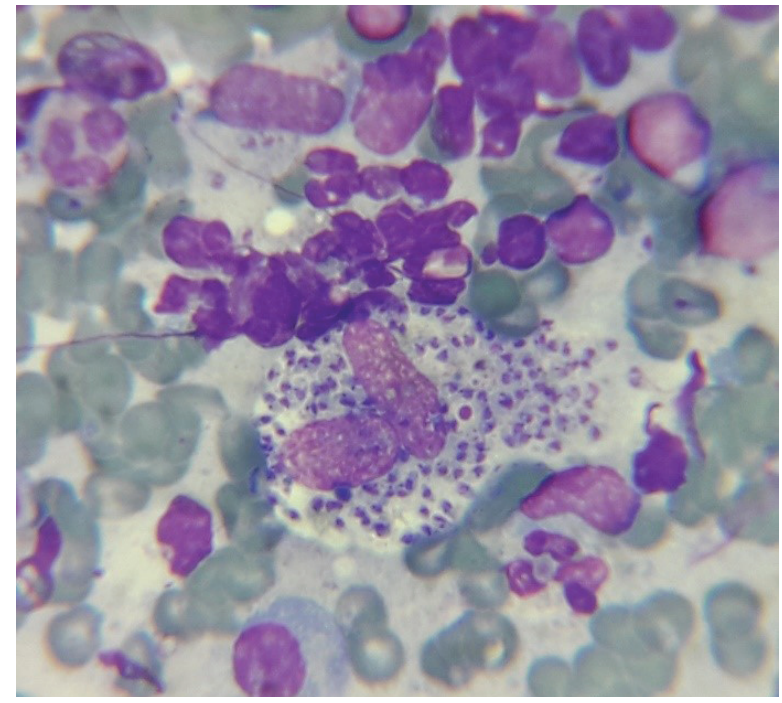

Figure 3: Giemsa stain, 100 x Photomicrograph showing macrophage packed with numerous amastogotes of Leishmania, approx. 2 to 4 -micron size. Plasma cell at the bottom. Extracellular LD bodies are also seen at the top amongst other inflammatory cells.

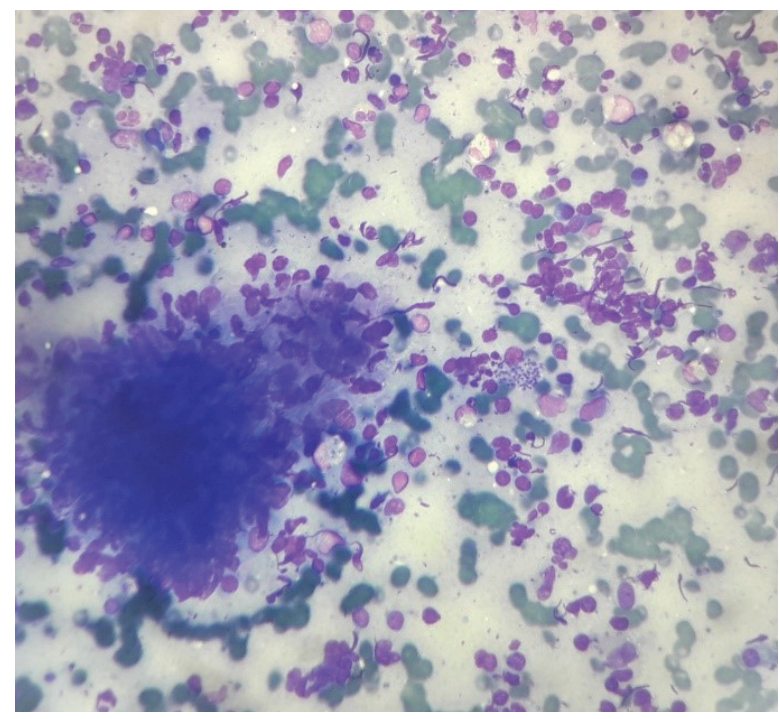

Figure 4: Giemsa stain, 40 x Photomicrograph showing well-formed epithelioid cell granuloma, macrophage with numerous intracellular LD bodies and mixed acute and chronic cell infiltrates in the background.

due to its rarity in our part. Moreover, there was delay in the presentation as the patients had to travel from the remote place to seek for medical advice.

Most of our patients had single lesion which is similar to the finding of Aara $\mathrm{N}$ et $\mathrm{al}^{9}$ and Galgamuwa LS et al. ${ }^{14}$ In our study, lesions were more common in face. Other authors have also reported similar findings. ${ }^{11-13}$ Upper limb involvement was common in the studies conducted by other authors. ${ }^{9,14,15}$ These finding suggest that exposed part of body like face and limbs are more prone to bite of sand fly. 
Ulcerated plaque was the commonest type of lesion in our study. Ulcerated plaque was also reported as the most frequent lesion by Aara $\mathrm{N}$ et al. ${ }^{9}$ In contrast to this, Sharma NL et al reported ulcerated nodules as the most frequent lesion. ${ }^{10}$

In our study, laboratory diagnosis of cutaneous leishmaniasis was performed by aspiration cytology alone which was different from other studies and English literature which recommends scraping, slit skin smear, biopsy, culture and PCR.

FNA is not a popular method of diagnosis of nonhealing ulcer. Aspiration of skin lesion have been reported in one study in Nepal by Jha A et al. ${ }^{16}$

FNAC is less time consuming, non-scar forming, easy to repeat, cheap, and confirmatory technique for the demonstration of parasite. We can also see other

\section{References}

1. World health organization. Media centre. Leishmaniasis. Available from: http://www.who. int/mediacentre/factsheets/fs375/en/ [Accessed on $30^{\text {th }}$ November 2017].

2. World health organization. Global Health Observatory data repository. Status of endemicity of cutaneous leishmaniasis. Data by country. Available from: http://apps.who.int/gho/data/ node.main.NTDLEISHCEND?lang=en [Accessed on 30 ${ }^{\text {th }}$ November 2017].

3. Pandey BD, Babu E, Thapa S, Thapa LB. First case of cutaneous leishmaniasis in Nepalese patient. Nepal Med Coll J. 2006;8(3):213-4.

4. Neupane S, Sharma P, Kumar A, Paudel U, Pokhrel DB. Cutaneous leishmaniasis: report of rare cases in Nepal. Nepal Med Coll J. 2008;10(1):64-7.

5. Kumar R, Ansari NA, Avninder S, Ramesh V, Salotra P. Cutaneous leishmaniasis in Nepal: Leishmania major as a cause. Trans R Soc Trop Med Hyg. 2008;102(2):202-3. https://doi.org/10.1016/j. trstmh.2007.10.017

6. Kayastha BM, Shrestha P, Shrestha R, Jahan R. Cutaneous Leishmaniasis:a case report. Nepal Journal of Dermatology, Venereology \& Leprology. 2009;8(1):27-30.

7. Adhikari RC, Shah M. Cutaneous leishmaniasis. Journal of Pathology of Nepal. 2017;7(2):1212-7. https://doi.org/10.3126/jpn.v7i2.18031

8. BariAU. Epidemiology of cutaneousleishmaniasis.J Pak Assoc of Dermatol. 2006;16:156-62.

9. Aara N, Khandelwal K, Bumb RA, Mehta RD, Ghiya BC, Jakhar R, et al. Clinco-epidemiologic study of cutaneous leishmaniasis in Bikaner, Rajasthan, India. Am J Trop Med Hyg. 2013;89(1):111-5. features like epithelioid cell granulomas, lymphocytes and plasma cells along with intra and extracellular organisms of 2 to 4 -micron size.

All our cases were positive for LD bodies. Thus, invasive procedures like biopsy and expensive PCR techniques were not done.

\section{Conclusion}

Cutaneous leishmaniasis is in increasing trend in Nepal. Implementation of vector control program along with health education may help in the control of infection. Due to the increasing clinical diversity of the disease, $\mathrm{CL}$ should be suspected as a differential diagnosis when dealing with chronic non-healing ulcer.

Financial disclosure: None.

Conflicts of interest to disclosure: None declared. https://doi.org/10.3126/jpn.v7i2.18031.

10. Sharma NL, Mahajan VK, Kanga A, Sood A, Katoch VM, Mauricio I, et al. Localized cutaneous leishmaniasis due to Leishmania donovani and Leishmania tropica: preliminary findings of the study of 161 new cases from a new endemic focus in Himachal Pradesh, India. Am J Trop Med Hyg. 2005;72:819-24.

11. Gurel MS, Ulukanligil M, Ozbilge H. Cutaneous leishmaniasis in Sanliurfa: epidemiologic and clinical features of last four years (19972000). Int J Dermatol. 2002;41:32-7. https://doi. org/10.1046/j.0011-9059.2001.01396.x

12. Yemisen $M$, Ulas $Y$, Celik $H$, Aksoy $N$. Epidemiological clinical characteristics of 7122 patients with cutaneous leishmaniasis in Sanliurfa, between 2001 and 2008. Int J Dermatol. 2012;51:300-4. https://doi. org/10.1111/j.1365-4632.2011.05059.x

13. Srivastava D, Vyas MC, Joshi CK. Clinicoepidemiological study of cutaneous leishmaniasis in Bikaner (Rajasthan). J Commun Dis. 1987;19:326-31.

14. Galgamuwa LS, Sumanasena B, Yatawara L, Wickramasinghe S, Iddawela D. ClinicoEpidemiological Patterns of cutaneous leishmaniasis patients attending the Anuradhapura Teaching Hospital, Sri Lanka. Korean J Parasitol. 2017;55(1):1-7. https://doi. org/10.3347/kjp.2017.55.1.1

15. Al Samarai AM, Alobaidi HS. Cutaneous leishmaniasis in Iraq. J Infect Dev Ctries. 2009;3:123-9.

16. Jha A, Gurung D. FNAC diagnosis of cutaneous leishmaniasis. J Nepal Med Assoc. 2013;52(192):624-6. 